\title{
Effect of Mesh Density on Finite Element Analysis Simulation of a Support Bracket
}

\author{
${ }^{* 1}$ Nicholas S. Gukop, ${ }^{1}$ Peter M. Kamtu, ${ }^{1}$ Bildad D. Lengs, ${ }^{2}$ Alkali Babawuya and ${ }^{1}$ Adesanmi Adegoke \\ ${ }^{1}$ Department of Mechanical Engineering, University of Jos, Nigeria \\ ${ }^{2}$ Department of Mechatronics Engineering, Federal University of Technology, Minna, Nigeria \\ \{gukopn | kamtup | lengsb | adesanmia\}@unijos.edu.ng | babawuya@futminna.edu.ng
}

Received: 09-MAY-2021; Reviewed: 04-JUN-2021; Accepted: 04-AUG-2021

http://dx.doi.org/10.46792/fuoyejet.v6i3.632

\begin{abstract}
Investigation on the effect of mesh density on the analysis of simple support bracket was conducted using Finite element analysis simulation. Multiple analyses were carried out with mesh refinement from coarse mesh of $3.5 \mathrm{~mm}$ to a high-quality fine mesh with element size of $0.35 \mathrm{~mm}$ under $15 \mathrm{kN}$ loading. Controlled mesh analysis was also conducted for the same loading. At the mesh size of 0.35 $\mathrm{mm}$, it has a maximum stress value of $42.7 \mathrm{MPa}$. As the element size was reduced, it was observed that below $1.5 \mathrm{~mm}$ (higher mesh density) there was no significant increase in the peak stress value; the stress at this level increased by $0.028 \%$ only. Further decreased of mesh size shows insignificant effect on the stresses and displacements for the high-quality fine mesh analysis. The application of Highquality mesh control analysis showed a significant reduction in the computation time by more than $90 \%$. Regardless of the reduction in computation time, the controlled mesh analysis achieved more than $99 \%$ accuracy as compared to high-quality fine mesh analysis.
\end{abstract}

Keywords- Computation time, Finite Element Analysis, Mesh density, Support Bracket.

\section{$\mathrm{T}$}

1 INTRODUCTION he influence of mesh density on finite element simulation is very important as it greatly affects the overall accuracy of finite element analysis (FEA) result and the performance of resource requirement use for the computation, such as computer capacity and solution time (Ghavidel et al., 2018). Finite Element Method is used for solving various problems of engineering, this method has been applied in the area of Structural mechanics (Haider, et al.,2018), Fluid mechanics (Lengs et al., 2021), and thermodynamics (Ekpu, 2021). The unique ability of Finite Element Analysis method to analyse complex structures has made it popular in the field of engineering, and a new direction in the analysis of complex engineering problems- such as the analysis of irregular shapes structures having different elements with varying material properties, and those with complex loading and boundary conditions. Many problems involving the afore mentioned conditions have been successfully solved using the finite element analysis method (Dubey, 2018).

Studies carried out by various researchers have shown that the accuracy of results obtained from finite element analysis (FEA) is strongly related to the appropriateness of the discretization. However, a smaller mesh will require higher computational resources to arrive at a solution. Therefore, it is logical to allocate finer mesh in the regions of interest (Bitencourt et al, 2015). Wang et al. (2016) examined the effect of mesh size on finite element analysis of heavy-duty cross rail using ANSYS and compared simulation and experimental results.

*Corresponding Author

Section C- MECHANICAL ENGINEERING \& RELATED PHYSICAL SCIENCES Can be cited as:

Gukop N.S., Kamtu P.M., Lengs B.D., Babawuya A. and Adegoke A. (2021): Effect of Mesh Density on Finite Element Analysis Simulation of a Support Bracket, FUOYE Journal of Engineering and Technology (FUOYEJET), 6(3), 34-38. http://dx.doi.org/10.46792/fuoyejet.v6i3.632
The study showed that when the mesh size of the element is reduced, the simulated result gets closer to the experimental result at initial simulation with a default mesh size, and an error of $16.39 \%$ was detected compared to the experimental. As the element size is reduced the error also diminishes up to when the mesh size gives the same result as the experimental. This shows the great influence of mesh size on the simulation analysis of crossrail. The study also showed that the smaller the element size, the higher the resource requirement.

Application of FEA in the investigation stress concentration under various loading conditions was conducted by various researchers and the studies showed that the selection of the proper size of the mesh is critical to any FEA simulation results. The previous studies have shown that models with smaller (or finer) element sizes yield more accurate results but requires longer computational time as in contrast with larger (or coarse) element models with less accurate results and usually have a shorter computing time. Furthermore, studies also pointed clearly out, that the computation time and the accuracy of any FEA study largely depend on mesh density (More \& Bindu, 2015., \& Dutt, 2015). Studies have shown that mesh size and density greatly affect the accuracy of FEA simulation such as the work of Babawuya et al. (2021) and Gukop et al. (2020). Thus, it is important to determine the optimum mesh size for a particular FEA. Therefore, the aim of this this study is to investigate the effect of mesh element size and density on finite element analysis simulation of a simple support bracket.

\section{MATERIALS AND MethodS 2.1 SOLIDWORKS SIMULATION SOFTWARE}

SolidWorks is a Computer-Aided Design software for mechanical design modelling and simulation. It is a solid parametric, feature-driven software developed for Windows operating systems. It is a package of engineering simulation programs based on the finite element method (FEM) capable of performing linear and nonlinear simulations (Kurowski, 2018). The finite 
element analysis modelling and the simulation analysis of the simple support bracket in this study were all carried out using the SolidWorks 2018 version installed in an 8 GB RAM computer with a $2.5 \mathrm{GHz}$ processor speed. The software was used in different stages of the current study, which includes the creation of the 3-D model of the support bracket, setting up the loading and boundary conditions, meshing of the model and the extraction of results.

\subsection{SimULATION PROCEDURE}

\subsubsection{Cad Modelling}

The 3-D of the support bracket shown in Figure 1, was modelled using SolidWorks. A 2-D sketch of the side view (L-shape) was drawn and converted into a 3-D model using extruded boss in the feature's environment. The following dimensions were used: height, length, and thickness are $70 \mathrm{~mm}, 60 \mathrm{~mm}$, and $10 \mathrm{~mm}$ respectively. The material properties of the support bracket are given in Table 1.

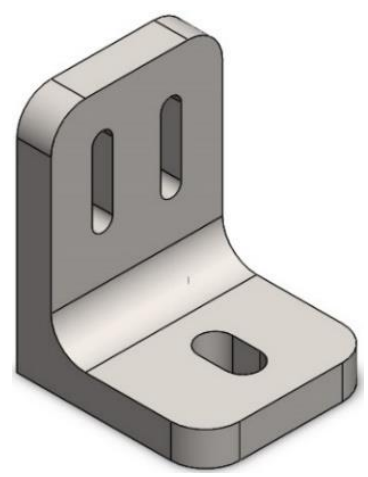

Fig. 1: 3-D Model of the Support Bracket Analysis Model.

Table 1. Mechanical Properties of the Support Bracket Material

\begin{tabular}{ll}
\hline \hline Property & Value \\
\hline Yield strength & $220.6 \mathrm{MPa}$ \\
Tensile strength & $399.9 \mathrm{MPa}$ \\
Elastic modulus & $210.0 \mathrm{MPa}$ \\
Poisson's ratio & 0.3 \\
\hline \hline
\end{tabular}

\subsection{LOADING AND BOUNDARY CONDITIONS OF FEA MODEL}

Fix geometry was applied to the back end of the support bracket to restrain all translational degrees of freedom of at the fixed end, and a load of $1500 \mathrm{~N}$ was applied as shown in Figure 2.

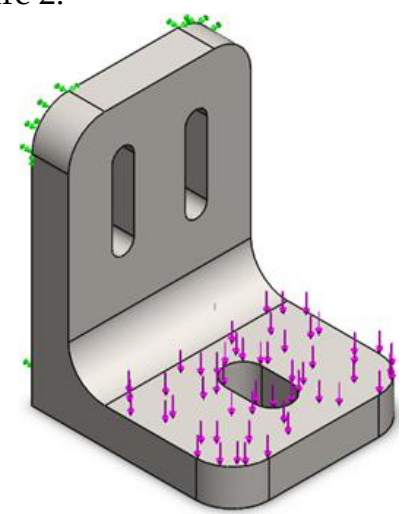

Fig. 2: The 3-D analysis model showing fixtures loading conditions.

\subsection{Mesh Generation ANd Mesh Sensitivity}

The initial analysis was conducted using the draft quality coarse mesh with an element size of $3.5 \mathrm{~mm}$. The software default mesh size was used as a starting point for mesh variation. To see the effect of mesh sizes on the analysis material, further mesh refinements were conducted from software default mesh of $3.5 \mathrm{~mm}$ followed by $3 \mathrm{~mm}, 2.5$ $\mathrm{mm}, 2 \mathrm{~mm}, 1.5 \mathrm{~mm}, 1 \mathrm{~mm}, 0.5 \mathrm{~mm}, 0.4 \mathrm{~mm}$ and $0.35 \mathrm{~mm}$.

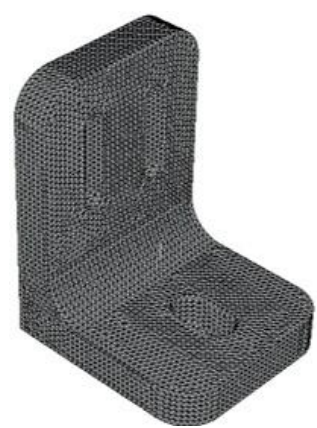

(a)

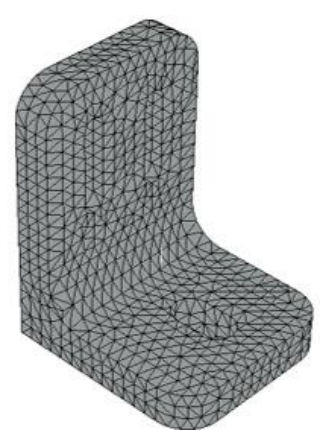

(b)
Fig. 3: (a) Fine Mesh and (b) Coarse Mesh Quality Plots.

Figure 3 shows meshed support bracket in coarse and fine mesh densities. Studies have shown that a single analysis cannot be used to determine the optimum mesh size for a particular FEA problem. Therefore, performing multiple analyses helps to ascertain the convergence of the mesh (Steffen \& Nudehi, 2018).

\subsection{Controlled Mesh Analysis}

There is a likelihood of localized stress concentration in components having sharp corners or bends, therefore, mesh refinement is required. The Mesh control specifies different element sizes at different regions in the model by creating smaller elements in critical locations. The creation of smaller elements in such locations improves the accuracy of results (Akin, 2010).

The controlled system of mesh was also applied to check the effect on computation time. The critical zones which are prone to higher stress were allocated the finer mesh sizes while the element sizes which are far away from the critical points are made coarser as shown in Figure 4.

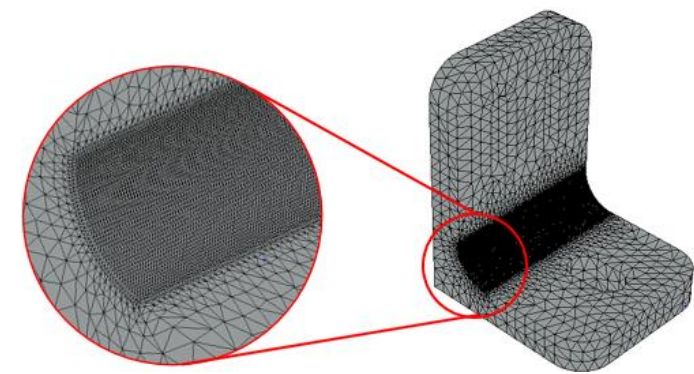

Fig. 4: Finite element model showing controlled mesh critical point

\subsection{Analysis Procedure}

Multiple simulation analyses were performed on the support bracket with successive analysis having a finer mesh than the previous while maintaining the same load and boundary conditions. The stress and displacement values over time were recorded with varying mesh sizes. 


\section{Results AND Discussion}

\subsection{EfFECT OF MESH DENSITY ON STRESS ANALYSiS}

The effect of the number of mesh element size on the stress of the bracket is shown in Figure 5. Maximum stress of $42.7 \mathrm{MPa}$ was recorded with corresponding element of $0.35 \mathrm{~mm}$ (see Figure 6) it can be observed that, as the number of elements gets higher (i.e., mesh density) the element sizes reduce. The peak stress increases but as the element size gets below $1.5 \mathrm{~mm}$ in size the stress begins to stabilise without significant change in the stress, the stress at this level increases by $0.028 \%$ and further decrease of mesh size will not have a significant effect on the stresses as seen from the percentage change in stress.

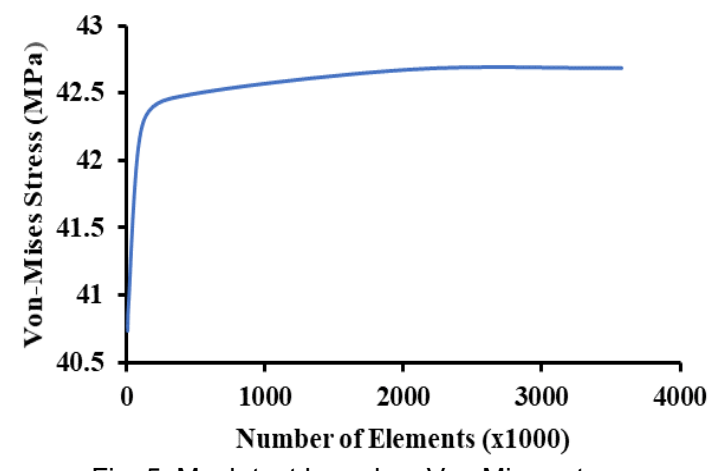

Fig. 5: Mesh test based on Von Mises stress

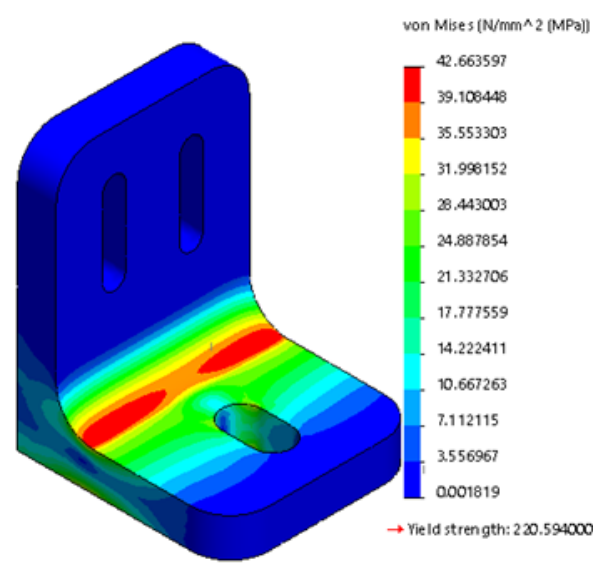

Fig. 6: Stress distribution on the support bracket

Figure 7, shows the graph of stress against the mesh density. From the graph, as can be seen from the Figure 7, that above a mesh density of 2020968 elements, the numbers of elements have no significant effect on the stress developed by the bracket as a result of the application of external load. The trend for the normal stress exhibits the same pattern as seen in figure 7 .

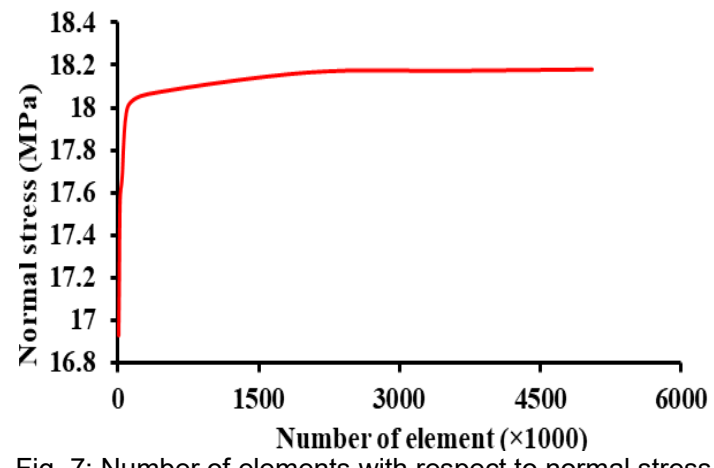

Fig. 7: Number of elements with respect to normal stress

\subsection{Effect Of Number Of ElemENT ON DisPlacement}

The plots obtained from the mesh test are given in Figure 8. The graph shows displacement versus the corresponding number of elements. It could be observed that, as the number of elements increases (as the element size gets smaller) the displacement becomes minimal approaching a limiting value, and this indicates a convergence of the solution. The graph indicates that the stiffness of the material decreases with smaller element size elements but becomes constant from a particular point regardless of the reduction in element size, indicating attainment of acceptable accuracy of the result.

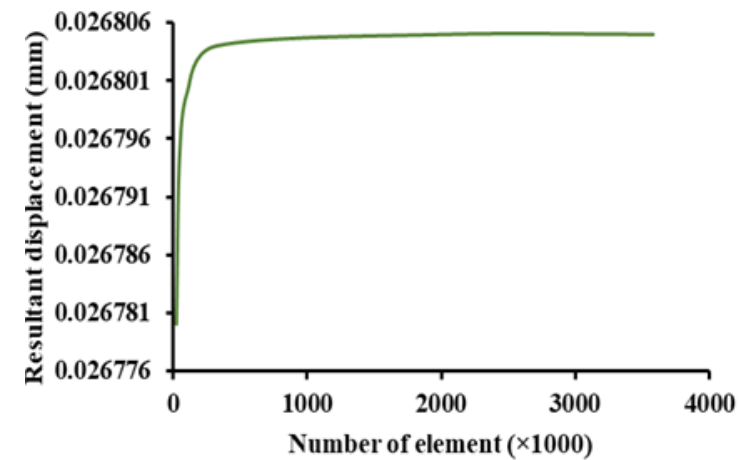

Fig. 8: Resultant displacement with respect to number of elements

\subsection{Effect of Number of Element on SOlUtion Time}

The relationship between the number of elements and the solution time is presented in Figure 9. The relationship shows a directly proportional trend in which the increase in the number of elements causes an increase in the solution time as also seen from the study conducted by Fondjo \& Dzogbewu, (2019). The increase in the number of elements which is associated with the reduction in element size also causes the numbers of the degree of freedom thereby requiring more time for computation.

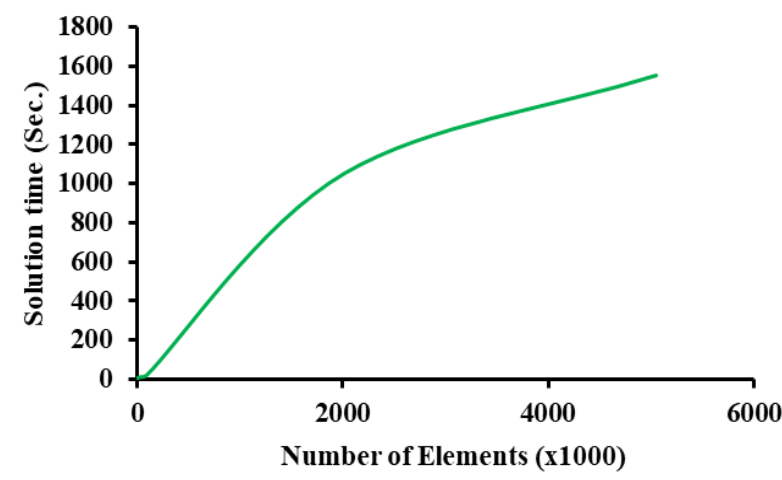

Fig. 9. Solution time with respect to number of elements

\subsection{Impact of Controlled Mesh on Simulation RESUlTS}

Table 2 shows the comparison between the high-quality fine mesh with the high-quality controlled mesh from the study. The result shows that for von Mises Stress and displacements, there is more than $99 \%$ agreement between the high-quality fine mesh and the controlled mesh analysis. For solution time, it is seen that there is a large disparity between the high-quality mesh and the controlled mesh. This disparity is due to the controlled mesh which assigns the finest mesh to high-stress zones and coarse mesh at low-stress zones. This combination 
has greatly reduced the number of degrees of freedom and consequently reduce the solution time. The application of the controlled mesh has greatly reduced the computation time and still achieves more than $99 \%$ accuracy.

Table 2. Percent Difference (\%) High-Quality Fine Mesh Vs High-Quality Mesh Control

\begin{tabular}{cccc}
\hline \hline & $\begin{array}{c}\text { High quality } \\
\text { fine mesh }\end{array}$ & $\begin{array}{c}\text { High quality } \\
\text { mesh control }\end{array}$ & $\begin{array}{c}\text { Percent } \\
\text { difference } \\
(\%)\end{array}$ \\
\hline $\begin{array}{c}\text { Von Mises } \\
\text { Stress (MPa) }\end{array}$ & 42.70752 & 42.66359 & 0.103 \\
$\begin{array}{c}\text { Displacement } \\
\text { (mm) }\end{array}$ & 0.026805 & 0.026781 & 0.089 \\
$\begin{array}{c}\text { Total } \\
\text { Elements }\end{array}$ & 5051491 & 89818 & 98.22 \\
$\begin{array}{c}\text { Total } \\
\text { solution } \\
\text { time (s) }\end{array}$ & 1667 & & \\
\hline \hline
\end{tabular}

The high-quality fine mesh and the controlled mesh analyses were compared to the manual calculation; the result shows that the stress level and displacement yield about $5 \%$ difference and $1 \%$ difference for the stress and displacements respectively as show in table 3 and 4 .

Table 3. Percent difference (\%) High quality fine mesh vs Manual calculation

\begin{tabular}{cccc}
\hline \multicolumn{4}{c}{ Manual calculation } \\
& $\begin{array}{c}\text { High quality fine } \\
\text { mesh }\end{array}$ & $\begin{array}{c}\text { Manual } \\
\text { calculation }\end{array}$ & $\begin{array}{c}\text { Percent } \\
\text { Difference (\%) }\end{array}$ \\
\hline $\begin{array}{c}\text { Von Mises } \\
\text { Stress (MPa) }\end{array}$ & 42.707523 & 40.499 & 5.17 \\
$\begin{array}{c}\text { Displacement } \\
(\mathbf{m m})\end{array}$ & 0.026805 & 0.02647 & 1.25 \\
\hline \hline
\end{tabular}

Table 4. Percent Difference of Controlled Mesh vs Manual

\begin{tabular}{c|ccc}
\hline \multicolumn{4}{c}{ Calculation } \\
\hline & $\begin{array}{c}\text { Controlled } \\
\text { mesh }\end{array}$ & $\begin{array}{c}\text { Manual } \\
\text { calculation }\end{array}$ & $\begin{array}{c}\text { Percent } \\
\text { difference } \\
(\%)\end{array}$ \\
\hline $\begin{array}{c}\text { Von Mises } \\
\text { Stress (MPa) }\end{array}$ & 42.6635 & 40.499 & 5.07 \\
\hline $\begin{array}{c}\text { Displacement } \\
(\mathbf{m m})\end{array}$ & 0.02678 & 0.02647 & 1.16 \\
\hline \hline
\end{tabular}

With a $98 \%$ difference in the number of elements, the controlled mesh analysis having 89818 elements achieved about $99.9 \%$ agreement with the results of the highquality fine mesh with 5051491 elements. With the mesh control approach, similar accurate results for the displacements were achieved at a considerably lesser computational time as shown in table 2 . This significant reduction in the computation run time is associated with the lesser number of equations to solve as result of lesser number of degrees of freedom and elements. The study shows that the mesh-controlled analyses with fewer elements is capable of giving reasonably accurate result at lesser computation time as compared to the analyses done with the refined high-quality fine mesh.

\section{Conclusion}

Investigation on the effect of mesh size and density on the FEA of a support bracket was conducted; the parameters studied are stress level, deformation and computation time. To achieve the aim of this research work, a 3-D model of the support bracket was produced using FEA software, meshed using various mesh densities, boundary conditions applied and finally the simulation setup was executed for the of the meshed densities.

The conclusion was that the stress at a mesh size is 0.35 $\mathrm{mm}$ was found to be $42.7 \mathrm{MPa}$. and from the relationship exhibited between the mesh density and stress, it can be concluded that, there is no significant increase in the stress level of the support bracket while the element size is smaller than $0.5 \mathrm{~mm}$. Also, maximum displacement of $0.026805 \mathrm{~mm}$ was recorded with $0.35 \mathrm{~mm}$ element size, however from the element size of $0.5 \mathrm{~mm}$ and below, the, there is no significant variation in the resultant displacement of the support bracket. As the number of mesh elements gets smaller which indicates higher mesh density, the solution time also increases. Thus, one can conclude that the increase in the mesh density is directly proportional increase solution time. The application of high-quality mesh control analysis reduced significantly the computation time by more than $90 \%$ and still achieves more than $99 \%$ accuracy as compared to high-quality fine mesh analysis.

The full model of the support bracket was analysed in this work. Further works can be done on the support bracket by taking advantage of the symmetry of the shape, an FEA analysis can be done using haft of the mesh used. Also, various loading smaller and greater than $15000 \mathrm{~N}$ can be investigated. Lastly, the position of the load and its complexity (its direction) can be varied to investigate it effect on the mesh requirement.

\section{REFERENCES}

Akin, J. E. (2010). Finite element analysis concepts via SolidWorks. Hackensack, New Jersey, USA: World Scientific Publishing.

Babawuya, A., Ekanah B.S., Kamtu, P. M., Okegbele O.J., Jiya J., \& Agongo O. (2021). Effect of Number of Node on the Deflection of a Simply Supported Beam Using Finite Element Analysis. ABUAD Journal of Engineering Research and Development, 4(1), 3137

Bitencourt Jr, L. A., Manzoli, O. L., Prazeres, P. G., Rodrigues, E. A., \& Bittencourt, T. N. (2015). A coupling technique for nonmatching finite element meshes. Computer methods in applied mechanics and engineering, 290, 19-44.

Dubey, R. K. (2018). Report on Studying the Effect of Mesh Density on Finite Element Analysis and Establish an Optimal Mesh Density for Finite Element Analysis of a Bridge Deck under the effect of Self-weight and Vehicular dynamic Load. International Journal of Advance Research, Ideas and Innovations in Technology, 9(2), 1-9.

Dutt, A. (2015). Effect of mesh size on finite element analysis of beam. International Journal of Mechanical Engineering, 2(12), 8-10.

Ekpu, M. (2021). Effect of Elevated Temperatures on SAC305 Solder Alloy Thermal Interface Material in a Microelectronic Assembly. FUOYE Journal of Engineering and Technology, 6(1), 7781.

Fondjo, A. A., \& Dzogbewu, T. C. (2019). Assessment of Stress Raiser Factor Using Finite Element Solvers. Universal Journal of Mechanical Engineering, 7(6), 367-379. 
Ghavidel, A., Mousavi, S. R., \& Rashki, M. (2018). The effect of FEM mesh density on the failure probability analysis of structures. Korian Society of Civil Engineers Journal of Civil Engineering, 22(7), 2370-2383.

Gukop, N. S., Kamtu, P. M. and Zwalnan, S. (2020). Analysis of Indentation Test Using SolidWorks Simulation. Emerging Advances in Integrated Technology, 1(1), 28-37.

Haider, A. A., Kumar, A., Chowdhury, A., Khan, M., \& Suresh, P. (2018). Design and structural analysis of connecting rod. International Research Journal of Engineering and Technology, 5(5), 282-285.

Kurowski, P. (2018). Engineering Analysis with SolidWorks Simulation 2018. SDC Publications.

Lengs, B.D., Gukop, N.S., \& Adesanmi, A. (2021). Numerical Investigation of Phase Distribution of Dispersed Water in Oil Flow in a Pipe with Valve. ABUAD Journal of Engineering Research and Development, 4(1) 84-97.

More, S. T. \& Bindu, R. S. (2015). Effect of mesh size on finite element analysis of plate structure. International Journal of Engineering Science and Innovative Technology,4 (3), 181-185.

Steffen, J., \& Nudehi, S. (2018). Analysis of machine elements using SolidWorks simulation 2018. SDC Publications.

Wang, J., Chen, J., Guo, T., Song, B., \& Guo, D. (2016). Element size effect on the analysis of heavy-duty machine cross-rail. In 2016 4th International Conference on Machinery, Materials and Computing Technology, (pp. 963-969). Atlantis Press. 